\title{
Veritas, Unitas, Caritas, en san Agustín
}

Tres vocablos, tres imanes, tres surtidores de luz en la vida de Agustin que nace en Tagaste un 13 de noviembre del año 354 y muere en Hipona el 28 de agosto del 430. Con su doctrina enriqueció la Iglesia santa de Dios y con su vida, a partir de su conversión el 387, dejó un ejemplo a imitar a todos los seguidores de Cristo.

Hombre "verdad" ha sido calificado en nuestros dias, con intuición certera. Apasionado por la verdad la busca en su juventud en el dualismo maniqueo o, en la duda de su hallazgo, se sitúa en el umbral de la Academia para venir a recalar su inquietud después de incontables singladuras en la ensenada de la Iglesia católica: "Yo, escribe en sus inimitables Confesiones, tenía hambre y sed de Ti mismo ;oh Verdad! en quien no hay mudanza ni oscuridad momentánea" 1 .

La búsqueda de la verdad, confiesa el santo a su amigo Honorato, enredado aún entre las espinas del error, fue siempre pasión de su juventud. Ahora vive alegre en la paz de la Iglesia de Cristo la única verdadera ${ }^{2}$.

La verdad como meta de su peregrinar, verdad en la ciencia, verdad en la fe, verdad en el ser, verdad en la acción y en la vida. Fue el señuelo de la verdad el que hizo picár al joven Agustín - -cupidus veri"- el anzuelo de un dualismo absurdo ${ }^{3}$. La luz de una aparente facilidad para resolver el problema pavoroso del mal deslumbró al retórico de Cartago que, engreído en su saber, consideraba la religión de Mónica como cuentos para viejas o niños. Luego viene el desencanto, la duda, el desánimo hasta que amanece en su alma la hora del Dios-Verdad. Ahora tiene plena certeza de haber

1. Confessiones III, 6: PL 32, 686-687.

2. De utilitate credendi I, I: PL 42,65 ; cf. Ch. BOYER, L'idée dé la Verité dans la philosophie de S. Augustín. Paris, 1920.

3. De utilitate credendi I, 2: PL 43,66 . 
encontrado la luz de la fe en la Iglesia católica única depositaria de la verdad ${ }^{4}$.

Las etapas recorridas en su afanosa búsqueda de la verdad quedarán marcadas por una madre, la doctrina de Ambrosio, la disciplina de la fe que es firme adhesión a la luz. La fe ancla su firmeza en Cristo, Verdad indeficiente y eterna. Creer es asentimiento firme a la autoridad de un Dios que adoctrina y se revela en los Padres $y$, en la plenitud de los tiempos, en su Palabra ${ }^{5}$.

Para salvarse basta crer en Dios y en Cristo perpetuado en su Iglesia. Su axioma es "creer para entender". Es una exigencia del alma una vez incorporada a la vid de la que el creyente es pámpano vivo y fecundo ${ }^{6}$.

Pablo define la fe como un obsequio racional y Agustín utilizará, al servicio de la fe, la filosofía de los neo-platónicos ${ }^{7}$. Es un método, no un camino; un andamiaje, no una construcción, porque la certeza de la fe supera - nunca contradice- la certeza de la filosofía. Para razonar acerca de los misterios es necesario limpiar los ojos de prejuicios maniqueos y adherirse, como a tabla salvadora, a la verdad revelada. Limpieza de alma condición esencial para intuir la verdad ${ }^{\text {s. }}$

Camino, verdad y vida es Cristo, el Señor. Su palabra es luz y calor, "agua trasparente que apaga la sed del peregrino de las cumbres y se hace camino al creer ${ }^{9}$. Si es un contrasentido dar nuestro asentimiento al que nos habla sin previo aval de su honestidad y saber ${ }^{10}$, no lo es creer en la Palabra-Verdad y adherirnos a su mensaje de salvación llevado a todos los cuadrantes del mundo por los misioneros de la Iglesia católica ${ }^{11}$.

La autoridad de la Iglesia católica enraíza en el consentimiento

4. De utilitate credendi VIII, 20: PL 43,79: "Sequere viam catholicae disciplinae, quae ab ipso Christo per Apostolos usque manavit, ab hinc ad posteros manatura est".

5. De utilitate credendi XIV, 31: PL 43,86.

6. De utilitate credendi XV, 35: PL 43,88.

7. Contra Acad. III, 43: PL 32,957: "Apud platonicos me interim quod sacris non repugnat reperturus esse confido": cf. R. JOLIVET, S. Augustin et le Néoplatonisme, Paris, 1932; D. N. DERISI, "Determinación de la influencia neoplatónica en la formación del pensamiento de S. Agustín": Sapientia 9 (1954) 272-287.

8. De utilitate credendi XIII, 29: $\mathrm{PL} 42,86$.

9. De utilitate credendi XIV, 31: PL 42,87.

10. De utilitate credendi XIV, 31: $\mathrm{PL} 42,87$.

11. De spiritu et litt. XIX, 32: PL 44,220; De doctrina christiana. II, 28 : PL 34,56 ; Enarrationes in Ps. 73,25 : PL 36,944: "Videat qui potest, credat qui non potest esse Deum". 
universal de los pueblos y en la tierra profunda de los milagros ${ }^{12}$. $\mathrm{Su}$ mismo calificativo de católica es garantía de verdad. Todas las demás confesiones o son cismáticas o heréticas, semillas de error, sólo la católica te preserva de error, te amamanta con leche de verdad, con pan de sabiduría, con la miel del Evangelio de Cristo pues ha sido fundada por la Verdad sobre la roca viva de Pedro y se continúa a través de los siglos en la sucesión de los obispos ${ }^{13}$.

Si quieres saber cuál es la verdadera iglesia lee las Escrituras, Antiguo y Nuevo Testamento y encontrarás la verdadera esposa de Cristo ${ }^{14}$

A la luz de Cristo imposible dudar de su verdad ${ }^{15}$. Para Agustín la autoridad de la Iglesia es garantía de certeza. Con cierta hipérbole afirma: "Evangelio non crederem, nisi me catholicae Ecclesiae commoveret auctoritas" ${ }^{16}$. ¿Habla la Iglesia? Cuestión resuelta ${ }^{17}$.

Norma, pues, de verdad, regla de fe es para el creyente la tradición de la. Iglesia y la Escritura ${ }^{18}$. Y si prefieres la brevedad y la claridad ahí tienes el símbolo bautismal donde encuentras quintaesenciada la verdad revelada ${ }^{19}$.

En su polémica contra los donatistas prueba Agustín la validez del bautismo administrado por un cismático, un hereje o un pecador, fundado en el sentir de la Iglesia universal ${ }^{20}$. Y, en determinadas circunstancias, la autoridad de un concilio plenario es sentencia inapelable de verdad, no porque la crea, sino porque la proclama, esclarece, afianza, margina toda duda y cierra los caminos al error ${ }^{2}$.

Famosa es su sentencia axiomática: "Roma locuta, causa fini$t a$ ". La verdad tiene siempre rostro ecuménico. Es la misma en Ro-

12. Contra ep. Fundamenti IV, 5: PL 42,175: "Tenet consensio populorum: tenet auctoritas miraculis inchoata, spe nutrita, caritate aucta, vestustate firmata”. Cf. Contra Faustum XIII, 13-14: PL 42, 289-290.

13. De vera :Religione VI, 10. PL 34, 127.

14. Serm. 29,3; PL 38,136: "Scripturas sanctae sunt, veraces sunt, inculpatae sunt".

15. Contra Faustum XI, 5: PL 42,256: "Habemus Christum verum atque veracem".

16. Contra ep. Fundamenti V, 6: PL 42, 172; Ep. 105,4,14: PL 33,401: "In Scripturis dicimus Christum, in Scripturis discimus Ecclesiam".

17. De pecctorum meritis et remis. I, 10,26: PL 44,124.

18. De doctrina christiana, III, 2,2: PL 34,65.

19. Serm. 59: PL 38,400: "Symbolum didicistis ubi est regula fidei vestrae brevis et grandis, brevis numero verborum, grandis pondere sententiarum".

20. De baptismo IV, 25,30: PL 43,174:"Quod traditum tenet universitas ecclesiae". cf. G. BAVAU: Bibliotèque Augustinienne, 29 (Paris 1964) 9-46.

21. Contra Cresconium I, 32,38: PL 43,465.

22. Contra Cresconium I, 33,39: PL 43,466. 
ma que en Jerusalén, en Atenas que en Cartago. La universalidad es nota de la verdad como lo es de la regla de $\mathrm{fe}^{22}$.

La Iglesia es tolerante en cuestiones opinables, intransigente en cosas que rozan la fe o las buenas costumbres: "Tamen quae sunt contra fidem vel bonam vitam... non approbat, nec tacet nec facit" ${ }^{23}$. La historia entera de la Iglesia es preclaro testimonio de este aserto de Agustín. Basta llevar la mano a un volumen de cualquier historia eclesiástica. La vida de bautizado del Doctor de la gracia es una lucha sin cuartel contra el error, la herejía o el cisma. Su doctrina puede compendiarse en contadas palabras: "Fe y verdad en la unidad de la Iglesia". Y aún más breve: "In cathedra unitatis doctrinam posuit (Christus) veritatis" ${ }^{24}$.

Tú, le dice al maniqueo Fausto, si quieres encontrar la verdad no la busques en la filosofía de los hombres sino en la Iglesia de Cristo. Hazte, pues, católico ${ }^{25}$.

Puede Agustín errar, los obispos pueden errar, los concilios provinciales equivocarse, las disputas entre escuelas teológicas pueden perturbar los ánimos de los fieles, pero la Iglesia fundada sobre roca es luz de verdad y unidad para todos los hombres de cualquier color o raza ${ }^{26}$.

Uno es el cuerpo de Cristo, uno el pueblo de Dios, uno el redil de la Iglesia, cátedra de sabiduria, reflector potente de la verdad, sin tacha ni arruga. Sin el pregón de la verdad no podría conocer a Cristo que es la misma verdad esencial ni tampoco la existencia de la Iglesia que participa de la verdad ${ }^{27}$.

\section{UNITAS, VERITAS}

Profundiza Agustín en el conocimiento de la Iglesia en su lucha contra el donatismo. Las intrigas de una fémina española "perniciossisima et factiossisima" ${ }^{28}$ y la venalidad de unos obispos reunidos en Cartago el 312 hacen posible el alumbramiento del cisma que

23. Ep. 55,19,35: PL 33, 221-222.

24. Ep. $105,5,16$ : PL 33,403 .

25. Contra Faustum XXIII, 6: PL 42,525

26: De baptismo III, 2,3: PL 43,140: "In cuius Ecclesiae communione securi sumus".

27. Enarrationes in Ps. LVII, 6: PL 36,679: "Ex veritatis ore agnosco Christum, ipsam Veritatem; ex veritatis ore agnosco Ecclesiam participem veritatis". 28. Contra ep. Parmeniani I, 3,5: PI 43,37; Contra litt. Petiliani II, 108, 247: PL 43,346; Contra Donatistas epistola VI, 3: PL 43,395. 
en la historia de la Iglesia se va a denominar donatismo ${ }^{20}$. Con este cisma queda rota la unidad de la túnica inconsútil de Cristo y se levanta altar contra altar, obispo contra obispo en el norte de Africa y en especial en la Numidia. El primer escrito contra los donatistas se titula "Psalmus contra partem Donati" ${ }^{0}$.

Quiere el pastor de almas poner al alcance de los fieles sencillos la historia y errores del donatismo y compone este salmo abecedario para ser cantado por el pueblo a imitación de lo que había hecho Parmeniano, obispo donatista, sucesor de Donato el grande en la sede de Cartago. El origen y doctrina del cisma queda en ese salmo condensado e invita al lector a ser juez imparcial de la verdad. Las 20 estrofas terminan con el estribillo - hypopsalmus - siguiente: "Omnes (vos) qui gaudetis de pace, modo verum iudicate" ".

Romper la unidad de la Iglesia es un pecado, rebautizar a los católicos que pasan al donatismo un crimen, juzgar inválidos el bautismo administrado por un traditor ${ }^{32}$ un error y una herejía. El corazón del pastor que es Agustín encuentra acentos de emocionada caridad e invita a los disidentes a entrar en la verdad de la unidad.

Paz en la unidad es lema agustiniano, fruto del amor. De esta paz en la unidad y amor que es Cristo mana, como de fuente caudal, la unidad de la Iglesia católica. El sermón 358, pronunciado dís antes de la célebre confrontación entre católicos y donatistas, (414), es una exhortación cálida a la paz en nombre del autor de la paz, del agricultor de la paz, del amador de la paz ${ }^{33}$.

La luz de la verdad se irá abriendo camino, pero es necesario moverse y el campeón de la unidad predica, escribe, dialoga con los donatistas, reta a los obispos del cisma a confrontaciones públicas,

29. No es mi intención tejer la historia y vicisitudes del donatismo. Remito al lector a las fuentes: OPTATO DE MILEVI, en sus 7 libros: PL 11, 835-1104; SAN AGUSTIN, Tratados antidonatistas: PL 43; M. PETSCHENIG: Corpus Scriptorum Ecclesiasticorum, tomos 51-53 (1908-1910); Oeuvres de saint Augustin: Bibliotèque Augustinienne . 28 (1963); 29 (1964); 30 (1967); 31 (1961); 32 (1965). Para los estudios sobre este tema citamos: P. MONCEAUX, Histoire littéraire de l'Afrique chrétienne des origines jusqu'à l'invasion arabe. IV: Le donatisme. V. S. Optat et le premiers écrivains donatistes (Paris 1920). VI: Litterature donatiste au temps de S. Augustin (Paris 1922). VII: S. Augustin et le donatisme (Paris 1923); cf. también L. ALFONSI, "Unità cattolica romana nel Psalmus contra partem Donati di S. Agostino": Studi romani 6 (1958) 407-412.

30. PL $43,23,32$.

31. Psalmus contra partem Donati I, 43,23: PL 43,23.

32. Traditor se llamó a todo aquel que durante la persecución del emperador Diocleciano (13 de mayo del 303) entregaba los libros santos a los gentiles para su destrucción.

33. Enarrationes in PS. 119,9: PL 37,1605: "Christus est pax nostra, qui fecit utraque unum". 
que éstos rehuyen siempre y escribe cartas que quedan sin contestar ${ }^{34}$. Agustín ataca a los donatistas desde todos los flancos y con todas las armas. Está en posesión de la verdad. El más grave error de los donatistas es romper una unidad de la Iglesia, rebautizar a los católicos, calumniar a Ceciliano de traditor, pues su inocencia quedó proclamada en Roma por el papa Melquiades en el 313, en el concilio de Arlés en el 314 y por el mismo emperador Constantino que sentencia a favor de Ceciliano en el $316^{35}$.

Para la Iglesia universal el bautismo administrado según la fórmula prescripta por Cristo es válido aunque sea administrado por un adúltero, un hereje, un cismático, un traditor, un impúdico o un miembro podrido del cuerpo de la Iglesia ${ }^{36}$.

A probar la validez del bautismo administrado por un pecador o cismático, y a resolver la espinosa cuestión del rebautizador que fue San Cipriano dedica Agustín sus siete libros sobre el bautismo ${ }^{37}$. La autoridad indiscutible de Roma sentenció contra el africano y la distinción entre apariencia y realidad, signo y contenido, sacramento y gracia sacramental fue un feliz hallazgo del genio del obispo de Hipona que resuelve múltiples antinomias ${ }^{38}$. El "aliud est sacramentum aliud virtus sacramenti" es axioma válido en todas las escuelas teológicas.

\section{UNITAS-CARITAS}

Alborea la verdad en el hontanar de la unidad en el amor. Es este "pondus" ${ }^{39}$ el que aconseja tolerancia con los donatistas vencidos e impulsa al pastor a buscar ovejas descarriadas y le da sabiduría para sanar heridas, olvidar ofensas y acoger con delicada ter-

34. Ep. 49, 51-53. 56-57 (ca. 399-400): PL 33,189,191, 194-195; 223-224.

35. Cf. F. MARTROYE, "La répresion du donatisme et la politique religieuse de Constantin et de ses successeurs en Afrique": Mémoires de la Societé national des Antiquaires de France (Paris, 1914) 93-140; J. P. BRISSON, Autonomisme et Christianisme dans l'Afrique romaine dès Septime Sévère a l'invasion vandale. Paris, 1958. J. CONGAR, "Introduction": Bibliotèque Augustinienne, 28 (1963) 30-32, pone ciertos reparos a la tesis de Brisson.

36. De baptismo III, 10,15: PL 43,144: "Baptismus Christi verbis evangelicis consecratus et per adulteros et in adulteris sanctus est, quamvis illi sint impudici et inmundi, quia eius sanctitas polui non potest et sacramento suo divina virtus assistit".

37. Cf. G. BAVAUD, "Introduction": Bibliotèque Augustinienne, 29 (Paris 1964) 3,47 .

38. De baptismo IV, 4: PL 43,199: "Disputans de sententia Cypriani... dico sacramentum baptismi et bonos et malos posse habere, posse dare, posse accipere".

39. Confessiones XIII, 9,10: PL 32,849. 
nura a cuantos regresan a la casa del Padre. Recibe a los obispos donatistas con todos los honores ${ }^{40}$. ¿Qué aman conservar su dignidad episcopal? De acuerdo, pero a condición de vivir en unidad "nobiscum estote" 4 .

En una misma cátedra, es evidente, que no pueden sentarse dos obispos, pero es también muy cierto que si no tienen ambos jurisdicción sí tienen los dos carácter episcopal. Agustín flamea al viento el lábaro de la paz en el amor de la unidad. Nada de violencias, ni revanchismos, ni asesinatos o violaciones de todo género a estilo de los cotopitas. Los métodos del terror no encajan en la pedagogia del amor cristiano. La ingente muchedumbre - populorum agmina - de los donatistas convertidos a la unidad de la Iglesia después de la conferencia del 411, son beneficiarios de esta paz en la unidad. En medio de las tinieblas del error donatista brilló una gran luz ${ }^{42}$.

Agustín es tolerante con las personas intransigente con el error. Pero la paciencia tiene un límite, la tolerancia una medida, el equilibrio un justo medio. La pasividad puede no ser virtud y en el pensamiento de Agustín detectan los estudiosos un viraje de noventa grados ${ }^{43}$.

En un principio no es partidario del uso de la fuerza contra cismáticos o herejes. Más tarde, a la vista de los intolerables excesos de los feroces circunceliones, más temibles que el rugido del león, piensa que la tolerancia cristiana no ata las manos a la justicia imperial de Roma".

El "amor pondus" le hace pedir clemencia para los culpables, la condonación de la multa pecuniaria para los vencidos. Por temperamento tiene marcada preferencia por los métodos de persuasión, del convencimiento, de la enseñanza, del amor ${ }^{45}$. En realidad es la praxis de la "Ecclesia-Mater" 46 .

40. Contra Gaudentium I, 37,48: PL 43,736; cf. L. J. LOF, "Gaudentius de Thamugadi": Augustiniana 17 (1967) 5,13.

41. Serm. 368,4: PL 39,1588: "Tollatur paries erroris, et simul simus".

42. Contra Gaudentium I, 24,7: PL 43,722: "Pax salubri lenitate tranquila, volentes invitat, non cogit invitos".

43. Cf. S. LANCEL, "Aux origines du donatisme et du mouvement des circumcelliones": Les Cahiers de Tunisie 15 (1967) 183-188; para el juicio de este estudio: Revue des Etudes Augustiniennes 15 (1969) 308-309.

44. Ep. 93,17: PL 33, 329-330: "Mea primitus sententia non erat nisi ad unitatem Christi esse cogendum, verbo esse agendum, disputatione pugnandum, ratione vincendum".

45. Serm. 295, 20: PL 38, 1348: "Sustineat eos mater piis visceribus sanandos, portet docendos, ne plangat mortuos". Cf. J. GALLAY, "La conscience dr la charité chez S. Augustin": Revue des Études Augustiniennes (1955) 1-20.

46. Serm. 119,4,4: PL 38 . 
Por añadidura el amor es algo así como una placa reveladora de la presencia del Espíritu. Si amas a Dios permanece en ti el Espiritu. Amar al que nos ama es dulce deber. Dios permanece en el que ama, pero no como contenido sino "ut te contineat" ".

La teologia de la Iglesia en la obra de Agustín es rica en imágenes: las bodas de Caná, la samaritana, el paralitico, la multiplicación de los panes en el desierto, el ciego de la piscina de Siloé, la unción de Betania, el templo, la casa, la ciudad de Dios, la pesca milagrosa son, en la pluma de Agustín bellos símbolos de la Madre Iglesia: "Vulva matris, aqua baptismatis" ${ }^{48}$.

La esposa del Cantar de los Cantares es la Iglesia católica, Cristo el esposo. Al Amado se le llama rey, a la esposa sulamita: En un lenguaje poético de enamorados se describen las relaciones de Cristo con su Iglesia. Los símiles son de una belleza fascinadora. Sentido eclesial en sentir de Agustín, tienen las palabras con melodía de arrullo del Esposo: "Unica es mi paloma, única mi perfecta" (Cant 6,9).

La paloma es simbolo de la paz. Interviene en el bautismo de Jesús y en esta escena del Jordán se identifica con el Espíritu Santo ${ }^{48}$. Es observador el obispo de Hipona. Sabe que las palomas viven en sociedad, vuelan en bandadas, no aman la soledad y cantan sus amores con tonada de brisa primaveral. Es imagen de la inocencia y de la pureza, de la unidad y de la paz, de la bondad y del amor, de la fidelidad y son monógamas como lo es la esposa de Cristo, su iglesia ${ }^{40}$.

En sus tratados antidonatistas y en particular en De Baptismo da Agustín el nombre de nombre de paloma a la iglesia "quae in sanctis est" es decir a la iglesia de los bautizados que viven su cristianismo, se aman en caridad y se dejan guiar por el Espíritu. Esta iglesia es casta púdica, sin mancha ni arruga de pecado (Ef. 5,27). Es la fuente sellada y el huerto cerrado del Cantar de los Cantares,

47. Cf. M. COMEAU, S. Augustin exégete du quatrièmé évangile (Paris 1930) 156-158; R. PALMERO RAMOS, Ecclesia mater en san Agustín. Madrid, 1970; P. RINETTI, "Sant'Agostino e l'Ecclesia Mater": Augustinus Magister, II (1954) 827-834.

48. Cf. A. FEUILLET, "Le symbolisme de la columbe dans le récits évangeliques du baptême": Recherches des Sciences Religeuses 46 (1958) 524-544; M. BONNADIERE, "Les Cantiques des Cantiques dans. S. Augustin": Revue des Etudes Augustinennes (1955) 225-237.

49. Serm. 60,3,4: PL 38,426: "Attende columbas in societate gaudere; ibique simul volant, simul pascuntur, communione gaudent, caritatem servant, gemitibus amoris murmurant". Cf. también In Iohannis evangelium tr. V, II; VI, 2; VI, 3,4: PL 35, 1419, 1425, 1426-1427; In Iohannis evangelium tr. I, 2: PL 35, 2035. 
edén con abundancia de aguas y frutos, que son los dones del Espiritu Santo ${ }^{50}$. No la iglesia "qualis nunc est", sino la iglesia del Reino "qualis futura est" 51 .

La unidad en el amor es clave y es vuelo, es paloma y es roca, es templo y es campo. El Espíritu derrama su gracia en los carazones de cuantos pertenecen a Cristo y viven en el seno de la católica. $\mathrm{Y}$ la caridad es fuerza unitiva, compago corporis... unitatis et pacis ${ }^{52}$. El simil de esposa y paloma no es sólo bella metáfora, sino espléndida realidad que da viveza a la representación, eficacia al razonamiento, profundidad a la idea, solidez a la eclesiologia que se ve plenificada en el Cristo total ${ }^{53}$.

La paz, el amor, la mutua concordia son dones de la paloma que aletea sobre las aguas en el Génesis y voló los océanos en el diluvio, y vivifica el cuerpo místico de Cristo. De ahí que el Espíritu sea principio fontal de unidad, de amor y de vida ${ }^{54}$.

En la unidad, comunión y concordia fundamenta Agustín su doctrina eclesiológica. Pero estas tres palabras no tienen el mismo sentido en el Doctor de la gracia y en Petiliano. Basta, para convencerse, leer despacio las Actas de la Conferencia de Cartago del año $411^{55}$. Agustín enseña que la unidad en el amor es obra de las tres divinas personas con atribución al Espíritu Santo. En la unidad, la verdad y el amor. "In cathedra unitatis doctrinam posuit caritatis" ${ }^{56}$.

Para una recta interpretación del pensamiento agustiniano conviene distinguir el nivel de los signos y el nivel de la realidad, el esse de la unidad y sus apariencias o signos. Así, por ejemplo, la eucaristia subsiste como símbolo de una realidad misteriosa y profunda. Si la esposa y el esposo son una carne, la Cabeza y los miembros son un cuerpo y el Espíritu su principio vital ${ }^{57}$.

50. De Baptismo VI, 3,5: PL 43,199; In Iohannis evangelium tr. VI, 15,17:

PL 35, 1432-1433; Ep. 98,5: PL 33,362.

51. Enarrationes in Ps. 9,12: PL 36,122.

52. Serm. 295,2,2: PL 38,1349; De baptismo III, 17,22: PL 43,149; Enarrationes in Ps. 149,2: PL 37,1949: In Iohannis evangelium tr. XXVII, 6: PL 35, 1618 ; Ep. 185,46 : PL 33,813 .

53. Contra Cresconium II, 14,17: PL 43,195; De baptismo V, 27,38.

54: Serm. 268, 4,4: PL 38,1231.

55. SERGE LANCEL, en su espléndida "Introduction" a las Actas de la Conferencia de Cartago del 411: Sources Chrétiennes, 194 (Paris 1974); II (1973); III (1975).

56. Ep. $105,5,16$ : PL 33,403 .

57. In Iohannis evangelium tr. IX, 8: PL 35, 1462. 
UNIDAD EN EL CRISTO TOTAL

La unidad y la caridad son dos hermanas gemelas inseparables. Donde hay amor hay unidad. La Iglesia, como tal, no puede subsistir sin caridad ni puede sostenerse en pie sin el Espiritu vivificador. Las tres saetas que Agustín díspara contra los donatistas son: Espíritu, unidad, amor.

El Espíritu Santo es la fuente exclusiva del amor y el amor es causa de la unidad. Los donatistas pecan contra el Espíritu Santo, contra el amor y contra la unidad. La doctrina del cuerpo de Cristo exige, según el sentir de Agustín, con lógica férrea la unidad de la Iglesia y su universalidad. "Sola, escribe, la Iglesia católica es el Cuerpo de Cristo, cuya Cabeza es el salvador de su cuerpo Fuera de este cuerpo el Espíritu Santo no vivifica a nadie..., nadie participa de la caridad divina, si es enemigo de la unidad" ${ }_{58}$.

Sólo en la Iglesia de Cristo existe el amor en la unidad ${ }^{59}$. Los que con todo conocimiento se separan de la unidad y de la caridad no forman parte del Cuerpo de Cristo que es la Iglesia. Existe incompatibilidad radical ${ }^{6}$. Los donatistas hicieron astillas la unidad y apagaron la llama de la caridad que florece en el jardín de la única iglesia verdadera que es la católica.

La eucaristía es signo de esta unidad y lazo de la caridad. El simbolismo es paulino y Augustín lo aprovecha oportuno contra los donatistas. "Este pan, dice, que veis en el altar, santificado por la palabra de Dios es el cuerpo de Cristo; este cáliz, o mejor, lo que contiene este cáliz, santificado por la palabra de Dios, es la sangre de Cristo, que se derrama por nosotros en remisión de nuestros pecados. Si lo recibis bien seréis vosotros lo mismo que recibís. Dice el Apóstol: "Somos muchos pero un solo pan y un solo cuerpo (1 Cor 10,17)... Somos un solo pan y un solo cuerpo. En el pan veis cómo debéis amar la unidad. ¿Por ventura fue hecho pan de un solo grano de trigo? ¿No eran muchos los granos? Antes de ser pan eran muchos granos; el agua los juntó después de molidos; porque si el

58. Ep. 185,11,50: PL 33,815. Cf E LAMIRANDE, “Anima Ecclesiae" chez S. Augustin": Revue des Études Augustiniennes 13 (1967) 319-320. La bibliografía sobre la doctrina del cuerpo místico de san Agustín es copiosa; remito para esto a T. VAN BAVEL, Répertoire bibliographique: de S. Augustin (1950-1960) núms. $41-58 ; 468 ; 4624-4671$.

59. Contra litt. Petiliani II, 77,172: PL 43,312: "Tenemus caritatem, si amplectimus unitatem; amplectimus autem unitatem, si eam non per verba nostra in parte confingimus, sed per verba Christi in unitate cognoscimus".

60. Contra litt. Petiliani II, 77,172: PL 43,311. 
trigo no se muele y se amasa con agua no puede ser pan" .61. El realismo de Agustín es innegable y el simbolismo evidente. Los sentidos perciben las formas, la fe intuye la presencia de Cristo. Si somos un Cristo, lo que está en el altar es un símbolo de nosotros mismos.

El pensamiento es platónico, to invisible es real, lo visible es trasparencia. El signo sacramental no es mera referencia sino símbolo mistérico del cuerpo real de Cristo y de su cuerpo místico que somos nosotros. Es, pues, el pan y el vino una imagen llena de contenido. La comunión alimenta la vida de la Iglesia y al mismo tiempo hace circular por las venas del alma la vida que es Cristo. Al compartir el pan y el vino se afirma la unidad de los participantes en el Cristo Total.

Un pan, dice Pablo, un cuerpo somos muchedumbre. El pan, santificado por la palabra de Dios es el cuerpo de cristo y es emblema del cuerpo místico. Comer y beber el cuerpo y sangre de Cristo representa y obra la unidad entre la Cabeza y los miembros ${ }^{62}$.

La unidad es, pues, nota esencial de la Iglesia, cuerpo de Cristo. Unión vertical y horizontal, unión con Cristo y con todos los miembros de su cuerpo místico, vivificados por el Espíritu, dador de la vida verdadera ${ }^{6}$. Lo que es el alma al cuerpo formado de arcilla, es el Espíritu en el cuerpo de Cristo, da vida, fortalece, hermosea y santifica ${ }^{64}$. Consiste la vitalidad interior en participar de la Vida por medio del Consolador, savia vivificante. Es siempre el Espíritu el que llama, atrae, enamora e invita a las cumbres.

Nos unimos a Cristo por el amor. El que ama al Padre ama al Unigénito del Padre; el que ama a Cristo cree en El, porque sin la fe no subsiste el amor y quien ama a Cristo vive en santidad y quien vive santamente recibe el abrazo del Padre ${ }^{65}$.

Esta unidad vital e interior se rompe por el cisma, por la herejía formal o por el pecado grave. Si la vida del alma es Dios, morimos cuando damos entrada al pecado y abandonamos a Dios que es Vita vitarum ${ }^{66}$.

61. Serm. 227: PL 38, 109-110; Serm. 272: PL 38, 1247-1248; Serm. 229: PL 38,1103 .

62. Cf. K. ADAM, Die Eucharistielehre des heiligen Augustinus. 1908; cf. T. VAN BAVEL, Répertoire bibliographique, núms. $1592-1605 ; 4015-4044 ; 4172 ; 4516-$ 4548 .

63. In Iohannis evangelium tr. XXVII; 6: PL 35,1618.

64. Serm. 257, 4,4: PL 38, 1231; Serm. 249, 3: PL 38; 1162-1163; Serm. 250 :

PL 3: PL 38, 1166.

65. Contra Iulianum IV, 3,22: PL 44,749.

66. De Civitate Dei XIII, 2: PL 41,377. 
Las especies eucaristicas son. signo de la unidad de la Iglesia y, a su vez, signo del cuerpo real de Cristo, pleroma de la unidad. Agustín bajo las apariencias de la eucaristía intuye un doble signo, el del cuerpo físico de Cristo y del cuerpo místico. "Cuando nos dio el signo de su cuerpo no dudó en decir: "Esto es mi cuerpo" "7.

Por ser sacramento de unidad tiene la eucaristia exigencias ineludibles. "Sé tú lo que comes" 68 . Exige la unidad ser uno con Cristo, permanecer unidos a la cepa, ser pámpano, no árido sarmiento, lavar el alma por la penitencia, borrar la culpa con la lejía de la gracia, perdonar como Dios perdona. La permanencia la exige el Maestro: "El que no permanece en Mí por la caridad, y en quien Yo no permanezco, no imagine que come mi cuerpo y bebe mi sangre, porque no comen la carne de Cristo quienes no son miembros de Cristo" 69 .

Los que desafinan en el amor, desentonan en la unidad. Los adúlteros, los que se unen a una hetaira, los que chupan la sangre de los pobres, los herejes o cismáticos, los sacrilegos mastican - premunt dentibus - el cuerpo de Cristo pero no les aprovecha por estar ayunos de caridad ${ }^{70}$. Vivir del espíritu de Cristo supone permanecer en el amor. "El que quiera vivir tiene de dónde vivir. Acérquese y crea; déjese incorporar para poder ser vivificado..., no sea miembro podrido... ni deforme... Sea apto, bello, sano, adhiérase al Cuerpo, viva de Dios y para Dios" ".

Permanecer en Cristo es permanecer en la unidad, en la vida, en el amor por que el Espíritu Santo no da vida sino a los miembros unidos al cuerpo de Cristo que es la Iglesia. Entre el comulgante y Cristo ha de existir una mutua inmanencia, una adhesión interpersorsal, una sincera y auténtica amistad ${ }^{72}$.

La Iglesia católica es jerárquica por voluntad de su fundador que quiso asentarla sobre la roca viva de Pedro y los poderes del averno son impotentes para destruirla. Iglesia admirable en sus santos, que predica la verdad, que guarda en algunos de sus miembros la virginidad. en otros la castidad conyugal y en todos vive la gracia del amor ${ }^{73}$.

67. Contra Adimantium XII, 3: PL 42,144.

68. Enarrationes in Ps. 48,3: PL 36,545; cf. A. SAGE. "L'Eucharistie dans la pensé d'Augustin": Revue des Études Augustiniennes 15 (1969) 200-240.

69. De Civitate Dei XXV, 4: PL 41, 742-743.

70. In Iohannis evangelium tr. LXII, 13,1: PL 35, 1802; Serm. 272,1: PL $38,1248$.

71. In Iohannis evangelium tr. XXV, 13: PL 35, 1613

72. In Iohannis evangelium tr. XXVII, 1: PL 35, 1616: "Signum quia manducat et bibit hoc est: si manet et manetur, si habitat et inhabitatur, si haeret ut non deseratur".

73. Serm. 267, 4,4; PL 38,1331. 
¿No es motivo de alegria? ¡Qué dulzura ver reinar entre los miembros del cuerpo místico la paz y la concordia! Somos un cuerpo, no desafinemos; guerra al cisma, a las desuniones, a las rivalidades, a las envidias y chismorreos. No seas ojo enfermo, ni miembros gangrenado, ni pie torcido, ni mano crispada o espalda jibo$\mathrm{sa}^{74}$.

La paciencia y la tolerancia son virtudes en la Iglesia de Dios, la violencia gildoniana propia de la iglesia donatista. Por sus frutos la conocereis. "Si perteneces al cuerpo de Cristo, únete a la Cabeza; tolera la cizaña si eres trigo; tolera la paja si eres grano; tolera los peces malos si eres bueno" 75 .

La verdadera y única Iglesia es la de Cristo, difundida por todo el orbe que sabe utilizar a los gentiles como campo de apostolado, a los herejes para profundizar en su doctrina, a los cismáticos donatistas como argumento de su estabilidad. Invita a unos y a otros; a éstos los abandona, a los que caminan se adelanta y a todos deja abierta la cancela para que puedan regresar al redil. Trata tú de formar a Cristo en todos sus hijos; utiliza la paja para proteger al grano y cuando venga Cristo en la gloria del Padre, bieldo en mano, purificará su era ${ }^{76}$.

Grano soterrado es Cristo que muere por su Iglesia, tiene sed del agua de tu cántaro y te espera sentado en el brocal del pozo, se fatiga buscándote por riscos y hondonadas y se alegra cuando te encuentra. Somos un hombre nosotros y Cristo. El cabeza, nosotros miembros ${ }^{77}$.

Con frecuencia olvida Agustín en sus sermones a donatistas y herejes y su palabra se hace llama, su acento es paternal y deja desbordarse libremente su imaginación y brotan entonces de sus labios las más bellas comparaciones. Si san Juan nos exhorta a vivir en caridad, Agustín añade que la cruz es la medida del amor. Su anchura se mide por el travesaño; la altura por el palo vertical que mira hacia el cielo, parte a la que se acomoda la cabeza de Cristo crucificado. simbolo de la esperanza, mientras la longitud es el balo que se hinca en tierra y significa la profundidad de la gracia ${ }^{78}$.

$\mathrm{Y}$ si la eucaristía es símbolo y es realidad Agustín descubre la

74. Enarrationes in Ps. 132,6: PL 37,1732.

75. Enarrationes in Ps. $132,40,8$ : PL 36,460 .

76. De vera Religione VI, 10: $\mathrm{PL} 34,127$.

77. Enarrationes in Ps. 100,3: PL 37,1285:"Cpm capite nostro unus homo sumus",

78. Ep. 140,26,64: PL 33,566; Serm. 53,13,16: PL 38, 371372. 
unidad en la pluralidad. Si el bautismo nos introduce en el seno de la Iglesia, nos hace hijos de Dios y herederos del reino y, miembros de Cristo, la eucaristía nos hace vivir en Cristo. Basta recordar el sermón del Maestro sobre el pan de vida pronunciado frente a los trigales de Cafarnaún (Jn 6, 51-54). Comer el cuerpo y beber la sangre de Cristo, el Señor, es identificarnos con su plenitud.

La católica es unidad de fe, unidad de bautismo, de esperanza y amor. Es santa con una santidad que entraña la gracia, la inhabitación de la Trinidad y un nuevo nacimiento en el bautismo. Es la única iglesia universal en el tiempo, desde el justo Abel hasta la consumación de los siglos. Cristo se introduce en nosotros por la fe, vive en nosotros por el amor. Nos adentramos en alta mar en la nao de la Iglesia pilotada por Cristo, que, con pulso firme, enfila rumbo a la eternidad feliz.

La Iglesia significa, pues, en Agustín unidad de fe, de esperanza y caridad. La Iglesia sacramento es la Iglesia viviente interiorizada en cada miembro del cuerpo de Cristo por las tres virtudes teologales que anclan nuestra mente y nuestro corazón en la esperanza de una posesión futura ${ }^{79}$. Nuestra unión con Cristo es la de un organismo espiritual vivificado por el Espíritu. El idealismo neoplatónico prepara la inteligencia del hiponense para filosofar sobre las tres virtudes.

Si la fe justifica, la esperanza alienta y la caridad une Unión en una doble vertiente, une con Dios y con los hombres. La expresión "unitatis sanctissimum vinculum" 80 tiene profundidad y altura. El amor a Dios nos eleva, el amor al prójimo nos realiza y es prueba de que amamos a Dios en expresión joánica. La consecuencia se impone: "Caritate sursum habitemus" 81 "

No es posible amar a Cristo y vivir en el cisma Quien ama a la Iglesia, ama a Cristo y posee el Espiritu, alma de la Iglesia. La amamos si permanecemos en la unidad y en la caridad ${ }^{82}$. Sacramento e Iglesia, elemento visible y realidad invisible, signo y concepto significado, canal y gracia es el eje sobre el que gira la disputa de Agustín con Petiliano, Gaudencio y Parmeniano. Para el obispo de Hipona la Iglesia católica es comunión en la unidad $^{83}$.

79. Enarrationes in Ps. 91,1: PL 37,117.

80. Contra litt. Petiliani II, 80,117: PL 43,314.

81. In Iohannis evangelium tr. XXXII, 7,9: PL 35,1645 .

82. In Iohannis evangelium tr. XXXII, 7,8: PL 35,1649.

83. Enarrationes in Ps. 149,2. PL 37, 1949; In Iohannis evangelium tr. XXXVII, 6: PL 35,1618: "Ut compaginet unitas, quae facit nisi caritas? Et caritas unde? Diffussa est incordibus nostris per Spiritum Sanctum qui datus est nobis" (Rom 5,5); cf. Ep. 185,46: PL 33,813 . 
Es la caridad vínculo que nos une a Cristo y a sus miembros. Unidos a nuestra Cabeza fructificamos en santidad y profundizamos en la verdad y en la unidad. La caridad, como la gracia, nos diviniza. Hay en Agustín como un intercambio entre gracia y caridad, aunque ésta, en el orden de la causalidad, es posterior, pero la infusión de las tres virtudes teologales es simultánea ${ }^{84}$ Caridad y gracia en el corazón de la vida sobrenatural, fuente de toda acción meritoria $^{85}$.

Conocemos también la conexión que Agustín establece entre la caridad y el Espiritu Santo que actúa permanentemente en las profundidades del alma, sin olvidar el cuerpo vivo que es la Iglesia. Los justos al poseer la vida de la gracia, pertenecen al cuerpo místico de Cristo. Agustín alienta a los que se han enfriado en la caridad, a los miembros enfermos, a no separarse del cuerpo de Cristo. "Preferimos, escribe Agustín, que sean curados dentro de la comunidad de la Iglesia a que sean separados de su cuerpo como miembros incurables" 86 .

Alborea la hora del triunfo En la conferencia de Cartago del 411 la doctrina de Agustín se impone por su contundencia. Una es la Iglesia de Cristo, santa, católica. Una en virtud del plan divino que la Escritura nos revela, como uno es Cristo, el Señor; santa por vocación, santa en los santos, porque el ser que Cristo le da es celestial, neumático; católica porque la vida que su divino fundador le comunica es capaz de reunir en El todas las cosas en el cielo y en la tierra.

La Iglesia que Agustín ama es una Iglesia que perdona y salva, redime y santifica. Constituímos con Cristo un solo cuerpo, somos una persona -unus homo-en Cristo. Es, en esta realidad divinizante de Cristo en nosotros y nosotros en Cristo, como se verifica la inmanencia de Cristo viviendo y actuando en su cuerpo místico que es la Iglesia.

Hemos llegado al 8 de junio de 411. Los donatistas han perdido en las dos sesiones anteriores -1 y 2 de junio - un tiempo precioso en cuestiones de procedimiento y otras minucias. Se presentan los documentos, se estudian las Actas de los concilios de Cirta (305) y

84. Ep. 55, 2,3: PL 33,205 .

85. Serm. $32,9,9:$ PL 38,200 .

86. Serm. 137, 1: PL 38,754: "Quicumque in caritate friguerit, infirmatur in corpore Christi. Sed potens est ille, qui iam exaltavit corpus nostrum, etiam infirma membra sanare; dum tamen non nimis impietate praecidantur, sed haereant corpori donec sanentur. Quidquid adhuc haeret corpori, non desperatae sanitatis est; quod autem praecisum fuerit, nec curari nec sanari potest". 
de Cartago (312), se aducen en favor de Ceciliano las decisiones del papa Melquíades (313), del concilio de Arlés (314) y el edicto del emperador Constantino (316) contra la donatistas.

Agustin que en las dos primeras jornadas se mantiene en la penumbra quiere ir al fondo de la cuestión. Emérito, obispo donatista, comete el error de exigir la lectura de su carta a Marcelino y que respondan, si pueden, los católicos. Agustín toma la palabra. La cuestión va a ser abordada en profundidad, se discuten temas esenciales: la causa de la Iglesia católica y la causa de Ceciliano. La intervención del obispo de Hipona es decisiva. Insensible a las injurias, paciente en las interrupciones, vigoroso en el ataque, hábil en la: defensa pulveriza los argumentos de sus adversarios. Las Escrituras divinas le proporcionan argumentos contundentes y el soplo del Espíritu barre el suelo del error donatista para quienes Africa sola huele a rosas, mientras el resto del mundo apesta ${ }^{87}$.

El edicto de Marcelino - vir clarissimus - contra los donatistas es el mazazo definito. Lux venit, clama Agustín, veritas fulget. La sentencia es firme. La bandera del cisma será arriada para siempre. Agustín exhorta a sus fieles a que lean las Actas de la Conferencia, depongan todo deseo de revancha y amen la unidad ${ }^{88}$.

Los sermones que Agustín pronuncia a raíz del edicto del legado imperial son un himno festivo a la paz ${ }^{89}$. Es la hora de la concordia no de la guerra, del amor no del resentimiento, del beso no del bofetón.

Abre Agustín su corazón a la caridad, sus ojos a la luz, mira al hermano, no al enemigo; condena el error, jamás la persona. La consigna para cuantos anhelen vivir del espíritu, es, os la diré con sus mismas palabras:

"Tenete caritatem, amate veritatem, desiderate unitatem" ${ }^{90}$.

$Y$ el premio en la eternidad.

LUIS ARIAS, OSA. MADRID.

87. Enarrationes in Ps. 21, 2.2: PL 36,171: "Africa sola bene olet, totus mundus putet".

88. Serm. 357, 3: PL 38, 1584: "Exhortor caritatem vestram ut exhibeatis illis - donatistis- christianam et catholicam consuetudinem".

89. Serm. 357,4: PL 38,172.

90. Serm. 267, 4,4: PL 38,1231. 